\title{
MEDICATIONS USED BY PREGNANT WOMEN: ANY SAFETY CONCERNS?
}

\author{
JEY VONN KHOa, SIEW SIANG CHUA ${ }^{a *}$, RITA MOHAN DALLUMAL ${ }^{a}$, SITI ZAWIAH OMARc
}

aDepartment of Pharmacy, Faculty of Medicine, University of Malaya, 50603 Kuala Lumpur, Malaysia, bSchool of Pharmacy, Taylor's University, Lakeside Campus, 47500 Subang Jaya, Selangor, Malaysia, cDepartment of Obstetrics and Gynaecology, Faculty of Medicine, University of Malaya, 50603 Kuala Lumpur, Malaysia

Email: siewsiang.chua@taylors.edu.my

Received: 16 Nov 2016 Revised and Accepted: 20 Mar 2017

\section{ABSTRACT}

Objective: The use of medications during pregnancy may impose a potential risk to the fetus. Therefore, this study was conducted to determine the prevalence and safety of medications used by pregnant women.

Methods: A cross-sectional study was conducted on pregnant women who attended the antenatal clinic of a major teaching hospital in Malaysia, from January to April 2013. Data was collected via face-to-face interviews using a structured questionnaire.

Results: Of the 500 respondents in this study, 62\% (95\% confidence interval, CI: $57.7 \%$, 66.3\%) used at least one medication during their pregnancy and $30.8 \%$ (95\% CI: $26.8 \%, 34.8 \%$ ) took the medications during the first trimester. The classes of medications commonly used were analgesics $(26.8 \%)$, followed by cough and cold medications $(18.6 \%)$ and medications for gastrointestinal disorders $(11.8 \%)$. Among the 697 medications used by the respondents during pregnancy, most of them were relatively safe, with approximately $50 \%$ being classified under the Food and Drug Administration of the United States (FDA, US)-assigned pregnancy category B. However, seven potentially teratogenic medications were identified, including four antiepileptic drugs and an antimigraine medication which contained ergotamine.

Conclusion: This study found that a high proportion of pregnant woman consumed at least one medication during their pregnancy. The use of antimigraine medications containing ergotamine in pregnant women is of major concern as this medication could be obtained without a prescription in some countries, including in Malaysia. Therefore, it is essential for health care professionals to educate and counsel pregnant women on the safety of medications used.

Keywords: Pregnancy, Safety, Medication, First trimester, Teratogenic

(C) 2017 The Authors. Published by Innovare Academic Sciences Pvt Ltd. This is an open access article under the CC BY license (http://creativecommons.org/licenses/by/4.0/) DOI: http://dx.doi.org/10.22159/ijpps.2017v9i5.16057

\section{INTRODUCTION}

The concern about medication use during pregnancy was prompted by historical events such as the thalidomide tragedy which had resulted in birth defects and fetal deaths in thousands of babies [1]. Medications used during this period could cross the placenta and reach the fetus, depending on their lipophilicity, molecular size, concentration and metabolic pathway [2]. Therefore, the Food and Drug Administration of the United States (FDA, US) has established stringent regulations regarding the labeling and use of medications during pregnancy [3].

Petrie [4] stated that: 'In the past, a teratogen was simply considered to be an agent that caused a physical malformation. The definition of teratogen has been extended to include a broader range of abnormal development, including complete pregnancy loss, structural anomalies, abnormal growth in utero, and long-term functional defects'.

Currently, the safety and teratogenicity of medications in pregnancy are based on case reports, epidemiological and animal studies [5]. However, case reports and available studies were often confounded by a lack of documentation, records of dosages, duration, and concurrent medications used [2]. Additionally, animal studies may not accurately reflect human risk due to interspecies differences [6].

Despite the lack of safety data, studies in the US reported an average of 2.6 medications, whilst in North India, 1.7 medications were used during the first trimester of pregnancy, which is the period with high risk of teratogenicity [7-8]. In Malaysia, studies found that $51.4 \%$ of pregnant women used at least one type of herbal medication throughout their pregnancy and $73 \%$ used such medications during labour, with the hope to shorten and ease their delivery process [9-10].
Medication use during pregnancy is widespread and should be considered as a cause for public health concern [7-8, 11]. Pharmacoepidemiological studies are useful in assessing the extent of medication use by pregnant women and to determine the use of potentially teratogenic medications [11]. Such studies have been conducted in countries such as India, Pakistan and the US but are still scarce in Malaysia [7-8, 11]. Therefore, the present study was conducted to identify the types of medications used by pregnant women in Malaysia and to evaluate the safety of these medications, particularly during the first trimester of pregnancy.

\section{MATERIALS AND METHODS}

This is a cross-sectional study which was conducted in the antenatal clinic of a major teaching hospital in Malaysia. Pregnant women who attended the antenatal clinic from January to April 2013, were approached by two researchers to participate in the study. Those included in this study were pregnant women who were at least $21 \mathrm{y}$ old, in their second or third trimester of pregnancy and who could communicate in English, Malay or Mandarin.

During the study period, two researchers were stationed in the antenatal clinic. One of them approached any pregnant woman in the clinic (based on convenience sampling), explained the aim and procedure of the study to these women, and requested their consent to participate in the study. Upon receipt of a verbal consent by the potential respondent, the researcher proceeded to interview her using a structured questionnaire, which was developed based on a previous study [7]. The respondent was also informed that her medical records would be screened to obtain further information on her demographic data and gestational history.

To elicit the respondent's recollection of the medications used, a list of common health problems was used to enquire whether the respondent encountered any of the problems during her pregnancy 
and how she responded to such problems. Health supplements, blood and oxygen products were not considered as medications in this study. Medications used by the respondents were subsequently confirmed with their medical records or via telephone calls, as and when necessary.

Ethics approval was obtained from the medical ethics committee of the teaching hospital under study (Reference number: 956.31) prior to commencement of the study.

\section{Data analysis}

All data collected were entered into and analysed using the IBM SPSS Statistics for Windows, Version 20 (IBM Corporation, Armonk, New York). All data were subjected to descriptive analysis and presented as frequencies and percentages. Medications used by the respondents were classified according to the Anatomical Therapeutic Chemical (ATC) classification system, where the active ingredients of the medications were divided into different groups, according to their therapeutic use [12]. The safety of medications used during pregnancy was evaluated based on the FDA, US-assigned pregnancy categories, books on obstetrics and gynaecology, national and international guidelines, published studies and reviews papers $[1,4,13-15]$.

\section{RESULTS}

Out of the 545 pregnant women who were approached to participate in the study, $16(2.9 \%)$ were excluded as they did not meet the inclusion criteria. Another 29 women (5.3\%) declined to participate, giving a response rate of $94.7 \%$. The demographic characteristics of the 500 respondents are as shown in table 1 . The mean age (standard deviation, SD) of the respondents was 30.9 (4.4) years. Most of the respondents $(76.4 \%)$ were in their third trimester of pregnancy while the remaining $23.6 \%$ were in their second trimester. In addition, $43.4 \%$ of the respondents were having their first pregnancy during the interview while $66(13.2 \%)$ had a history of miscarriage.

Of the 500 respondents included in the analysis, $310(62 \%, 95 \%$ confidence interval, CI: $57.7 \%, 66.3 \%$ ) used at least one medication during their pregnancy, with $43.8 \%$ of the respondents using one or two medications. One of the respondents was using 10 and another was using 15 medications. A total of 697 medications were used by all the respondents which translated to an average of 1.4 medications per respondent. Amongst the medications used, a majority [675 (96.8\%)] were prescribed by a doctor while the rest were taken by the respondents without any prescription. In addition, 154 respondents (30.8\%; 95\% CI: $26.8 \%, 34.8 \%$ ) were using at least one medication during the first trimester of pregnancy but most of them (138 respondents) were using one or two medications except for one respondent who was using eight medications. The study determined that a total of 242 types of medications were used by the respondents. The number of medications used under each pregnancy safety category as stipulated by the FDA, US is summarized in table 2 .

Table 1: Demographic characteristics of respondents

\begin{tabular}{ll}
\hline Demographic characteristics & Frequency (\%) \\
\hline Age group (y) & $21(4.2)$ \\
$21-24$ & $186(37.2)$ \\
$25-29$ & $186(37.2)$ \\
$30-34$ & $91(18.2)$ \\
$35-39$ & $16(3.2)$ \\
$>40$ y old & \\
Ethnicity & $318(63.6)$ \\
Malay & $107(21.4)$ \\
Chinese & $62(12.4)$ \\
Indian & $13(2.6)$ \\
Others & \\
Highest education level & $1(0.2)$ \\
Primary education & $147(29.4)$ \\
Secondary education & $21(4.2)$ \\
Post-secondary education & $331(66.2)$ \\
Tertiary education & \\
Occupation & $59(11.8)$ \\
Medically related occupation & $441(88.2)$ \\
Non-medically related occupation &
\end{tabular}

aOthers include five foreigners, two Kadazans, and one each from the Bidayuh, Dusun, Iban, Murut, Kayan and Bajau communities.

Table 2: Summary of number of medications used during pregnancy under the various FDA, US-pregnancy safety categories

\begin{tabular}{lll}
\hline Pregnancy safety category & Any trimester & First trimester \\
\cline { 2 - 3 } & Frequency $\mathbf{( \% , \mathbf { N } = \mathbf { 6 9 7 } )}$ & Frequency $(\mathbf{\%}, \mathbf{N}=\mathbf{2 4 2})$ \\
\hline A & $1(0.1)$ & $1(0.4)$ \\
B & $361(51.8)$ & $129(53.3)$ \\
C & $100(14.3)$ & $24(9.9)$ \\
D & $5(0.7)$ & $4(1.7)$ \\
X & $1(0.1)$ & $0(0)$ \\
Unknown & $229(32.9)$ & $84(34.7)$ \\
\hline
\end{tabular}

Category A: Adequate and well-controlled studies have failed to demonstrate a risk to the fetus in the first trimester of pregnancy (and there is no evidence of risk in later trimesters).

Category B: Animal reproduction studies have failed to demonstrate a risk to the fetus and there are no adequate and well-controlled studies in pregnant women.

Category C: Animal reproduction studies have shown an adverse effect on the fetus and there are no adequate and well-controlled studies in humans, but potential benefits may warrant use of the drug in pregnant women despite potential risks.

Category D: There is positive evidence of human fetal risk based on adverse reaction data from investigational or marketing experience or studies in humans, but potential benefits may warrant use of the drug in pregnant women despite potential risks. 
Category X: Studies in animals or humans have demonstrated fetal abnormalities and/or there is positive evidence of human fetal risk based on adverse reaction data from investigational or marketing experience, and the risks involved in the use of the drug in pregnant women clearly outweigh potential benefits.

The 15 classes of medications most commonly used by the respondents during pregnancy are as shown in fig. 1 . The medications used by at least $1 \%$ of the respondents during pregnancy are shown in table 3. Table 4 shows the specific medications used by the respondents during the first trimester. The dosage of some medications such as aspirin (used by 13 respondents), were not available in this study and hence, the pregnancy safety category of these medications could not be determined.

\section{Classes of medications}

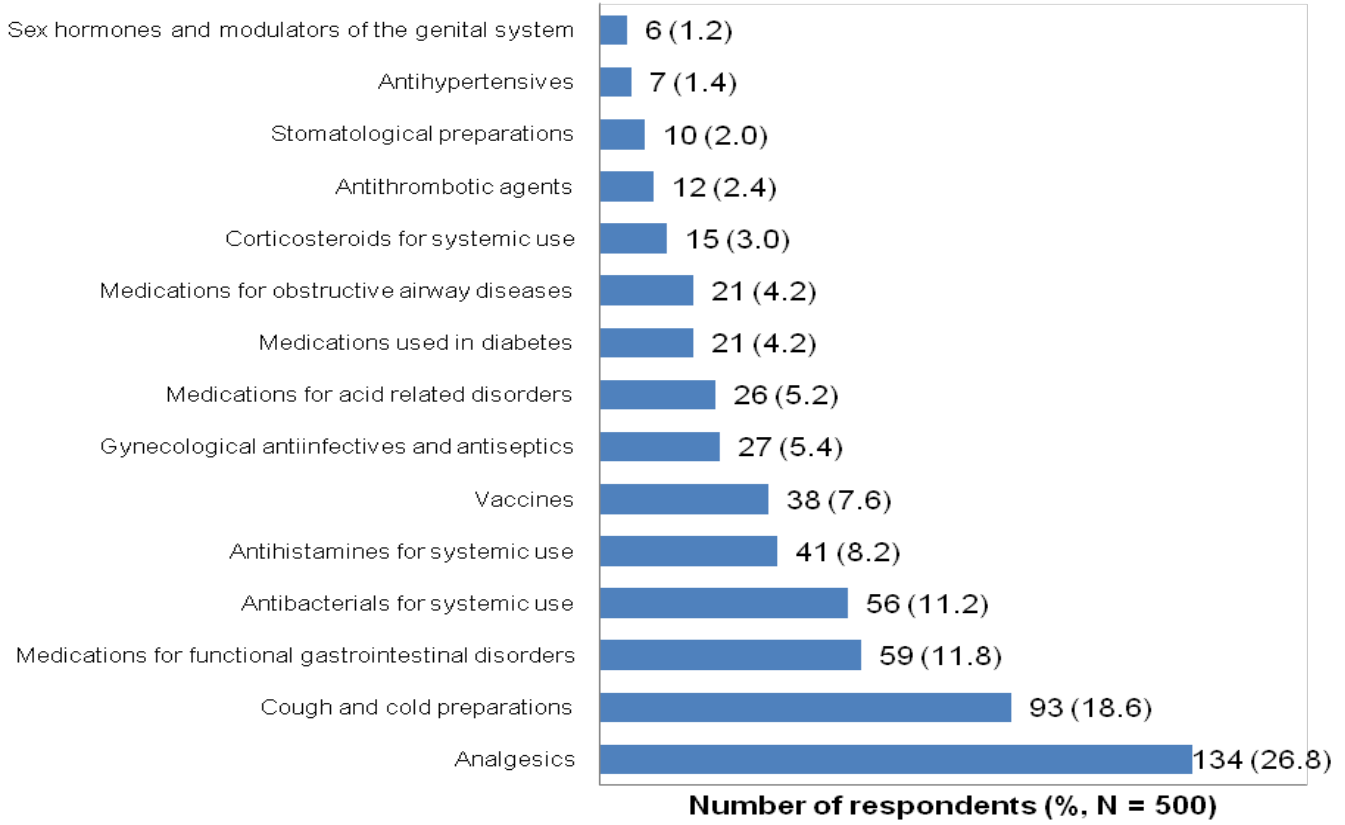

Fig. 1: Classes of medications used by more than $1 \%$ of the respondents

Table 3: Specific medications used by at least $1 \%$ of the respondents during pregnancy

\begin{tabular}{|c|c|c|}
\hline Pregnancy safety category & Medication & Frequency (\%) \\
\hline \multirow[t]{13}{*}{$\mathrm{B}$} & Paracetamol & $117(23.4)$ \\
\hline & Metoclopramide & $31(6.2)$ \\
\hline & Chlorpheniramine & $31(6.2)$ \\
\hline & Diphenhydramine & $29(5.8)$ \\
\hline & Clotrimazole & $25(5.0)$ \\
\hline & Cephalexin & $22(4.4)$ \\
\hline & Human monocomponent insulin & $17(3.4)$ \\
\hline & Metformin & $15(3.0)$ \\
\hline & Isophane insulin & $13(2.6)$ \\
\hline & Cefuroxime & $12(2.4)$ \\
\hline & Ranitidine & $9(1.8)$ \\
\hline & Amoxicillin & $5(1.0)$ \\
\hline & Cetirizine & $5(1.0)$ \\
\hline \multirow[t]{5}{*}{$\mathrm{C}$} & Tetanus toxoid vaccine & $38(7.6)$ \\
\hline & Salbutamol & $17(3.4)$ \\
\hline & Dexamethasone & $10(2.0)$ \\
\hline & Prospan ${ }^{\circledR a}$ & $7(1.4)$ \\
\hline & Methyldopa & $6(1.2)$ \\
\hline $\mathrm{C}, \mathrm{D}^{\mathrm{b}}$ & Aspirin & $13(2.6)$ \\
\hline \multirow[t]{7}{*}{ Unknown } & Unknown cough and cold medications & $61(12.2)$ \\
\hline & Unknown antiemetic & $29(5.8)$ \\
\hline & Unknown antipyretic & $15(3.0)$ \\
\hline & Unknown antibiotic & $14(2.8)$ \\
\hline & Magnesium trisilicate mixture & $9(1.8)$ \\
\hline & Thymol mouthwash & $7(1.4)$ \\
\hline & Dydrogesterone & $5(1.0)$ \\
\hline
\end{tabular}

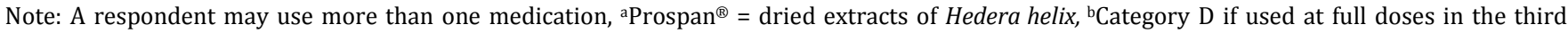
trimester 
Table 4: Medications used by the respondents during the first trimester of pregnancy

\begin{tabular}{|c|c|c|}
\hline Pregnancy safety category & Medication & Frequency (\%) \\
\hline A & Levothyroxine & $1(0.2)$ \\
\hline \multirow[t]{18}{*}{$\mathrm{B}$} & Paracetamol & $49(9.8)$ \\
\hline & Metoclopramide & $28(5.6)$ \\
\hline & Human monocomponent insulin & $7(1.4)$ \\
\hline & Chlorpheniramine & $7(1.4)$ \\
\hline & Diphenhydramine & $6(1.2)$ \\
\hline & Isophane insulin & $6(1.2)$ \\
\hline & Cephalexin & $5(1.0)$ \\
\hline & Metformin & $5(1.0)$ \\
\hline & Methyldopa & $4(0.8)$ \\
\hline & Ranitidine & $4(0.8)$ \\
\hline & Acyclovir & $1(0.2)$ \\
\hline & Cetirizine & $1(0.2)$ \\
\hline & Cloxacillin & $1(0.2)$ \\
\hline & Erythromycin & $1(0.2)$ \\
\hline & Lactulose & $1(0.2)$ \\
\hline & Loperamide & $1(0.2)$ \\
\hline & Nevirapine & $1(0.2)$ \\
\hline & Insulin aspart & $1(0.2)$ \\
\hline \multirow[t]{12}{*}{$\mathrm{C}$} & Promethazine & $1(0.2)$ \\
\hline & Seretide ${ }^{\circledR}$ inhaler h & $1(0.2)$ \\
\hline & Salbutamol & $11(2.2)$ \\
\hline & Budesonide inhaler & $3(0.6)$ \\
\hline & Budesonide nasal spray & $1(0.2)$ \\
\hline & Econazole & $1(0.2)$ \\
\hline & Fluticasone nasal spray & $1(0.2)$ \\
\hline & Heparin & $1(0.2)$ \\
\hline & Hydrocortisone & $1(0.2)$ \\
\hline & Combivent $^{\circledR}$ nebulizer ${ }^{c}$ & $1(0.2)$ \\
\hline & Combivir ${ }^{\circledR d}$ & $1(0.2)$ \\
\hline & Lamotrigine & $1(0.2)$ \\
\hline $\mathrm{C}, \mathrm{D}^{@}$ & Aspirin & $5(1.0)$ \\
\hline \multirow[t]{3}{*}{$\mathrm{D}$} & Sodium valproate & $1(0.2)$ \\
\hline & Propylthiouracil & $2(0.4)$ \\
\hline & Carbamazepine & $1(0.2)$ \\
\hline \multirow[t]{22}{*}{ Unknown } & Unknown antiemetic & $23(4.6)$ \\
\hline & A unknown cough and cold medications & $16(3.2)$ \\
\hline & Unknown antipyretic & $6(1.2)$ \\
\hline & Magnesium trisilicate mixture & $4(0.8)$ \\
\hline & Gaviscon ${ }^{\circledR f}$ & $3(0.6)$ \\
\hline & Dydrogesterone & $3(0.6)$ \\
\hline & Anusol ${ }^{\circledR}$ suppository ${ }^{b}$ & $2(0.4)$ \\
\hline & Herbal cough syrup & $2(0.4)$ \\
\hline & Veloxin $^{\circledR j}$ & $2(0.4)$ \\
\hline & Unknown antihypertensive & $2(0.4)$ \\
\hline & Unknown medication for bloatedness & $2(0.4)$ \\
\hline & Prospan ${ }^{\circledR g}$ & $2(0.4)$ \\
\hline & Thymol mouthwash & $2(0.4)$ \\
\hline & Unknown medication for gastritis & $2(0.4)$ \\
\hline & Alusil MPS ${ }^{\circledR a}$ & $1(0.2)$ \\
\hline & Ammonia ipecacuanha & $1(0.2)$ \\
\hline & Daflon ${ }^{\circledR e}$ & $1(0.2)$ \\
\hline & Drug study A & $1(0.2)$ \\
\hline & Ofloxacin ear drops & $1(0.2)$ \\
\hline & Oral rehydration salt & $1(0.2)$ \\
\hline & Sodium bicarbonate ear drops & $1(0.2)$ \\
\hline & Travisil $^{\circledR i}$ & $1(0.2)$ \\
\hline
\end{tabular}

Note: A respondent may use more than one medication, ${ }^{\circledR}$ Category D if used at full doses in the third trimester, aAlusil MPS ${ }^{\circledR}=$ aluminium hydroxide, magnesium trisilicate and simethicone; ${ }^{b}$ Anusol ${ }^{\circledR}$ suppository = zinc oxide, peru balsam and benzyl benzoate; ${ }^{c}$ Combivent ${ }^{\circledR}=$ ipratropium bromide and salbutamol; ${ }^{\mathrm{d} C o m b i v i r}{ }^{\circledR}=$ lamivudine and zidovudine; ${ }^{\mathrm{e}}$ Daflon ${ }^{\circledR}=$ diosmin and hesperidin; ${ }^{\mathrm{f}}$ Gaviscon ${ }^{\circledR}=$ sodium alginate, sodium bicarbonate and

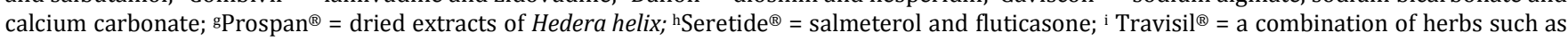
folium Adhatoda vasica, fructus Piper longum, fructus Piper nigrum, rhizomes Zingiber officinale, radix Glycyrrhiza glabra, fructus Emblica officinalis, rhizomes Curcuma longa, bark Acacia catechu, fructus Foeniculum vulgare, herbal Ocimum sanctum, fructus Terminalia chebula, fructus Terminalia belerica, rhizomes Alpinia galanga, folium Abrus precatorius, folium Mentha piperita; ${ }^{\text {iVeloxin }}{ }^{\circledR}=$ meclozine and pyridoxine

Levothyroxine (used by one respondent) was the only medication classified under pregnancy safety category A (table 4). Under category D were carbamazepine (used by one respondent) and sodium valproate (used by another respondent), and propyl- thiouracil which was taken by two respondents. The pregnancy safety categories of some medications could not be determined. Firstly, some of the respondents could not recall the name of their medications. Secondly, some medications such as magnesium 
trisilicate mixture, dydrogesterone and Gaviscon ${ }^{\circledR}$ (sodium alginate, sodium bicarbonate and calcium carbonate) were not assigned to any pregnancy safety categories by the FDA, US. Thirdly, some of the dosages of medications such as aspirin and pethidine were not recorded.

Seven potentially teratogenic medications were used by the respondents in the study. Four of the medications (carbamazepine, sodium valproate, lamotrigine and propylthiouracil) were used during the first trimester. The other medications that were used either in the second or third trimester of pregnancy included Cafergot ${ }^{\circledR}$ (ergotamine and caffeine) which was used by one respondent but this has been classified as Category X; diclofenac (used by one respondent and under Category D in the third trimester) and tramadol (used by 2 respondents during the second and third trimesters).

\section{DISCUSSION}

In the present study, $62 \%$ of the respondents used at least one medication during pregnancy. Another study reported the prevalence of medication use during pregnancy as $19.6 \%$ only [11]. The lower prevalence in the previous study could be attributed to the fact that only prescribed medications were included, and, it was conducted in a less developed country. Another study in the US showed a higher prevalence of medication use during pregnancy compared to the present study ( $93.9 \%$ versus $62 \%$ ). This US study also showed that the use of medications among pregnant women in the US increased with time [7].

In this US study, the average number of medications used by pregnant women regardless of the trimester had increased by $68 \%$, from 2.5 in 1976-1978 to 4.8 in 2006-2008 [7]. This increase could be attributed to women being more educated and less sceptical about consuming medications when they are not well [16]. However, this was much higher than that found in the present study, which was 1.4 medications. The difference in the findings may be due to the differences in culture of the respondents, and the prevailing health systems of the country.

The most commonly used classes of medication during pregnancy regardless of the trimester were analgesics, followed by cough and cold medications. Other studies found that the most commonly used medications were antibiotics and analgesics [8, 11]. This may be because the previous studies included only the use of prescription medications whereas, cough and cold medications were mainly nonprescription medications which can be purchased directly from a pharmacy.

Based on the FDA, US-assigned pregnancy safety category, most of the medications used by pregnant women in the present study were relatively safe, with approximately $50 \%$ of the medications used being classified under pregnancy safety category B. However, the frequency of use of these medications (even paracetamol) may increase its risks in the fetus. In addition, one-third of the medications used could not be classified as the names of the medications were not known.

Among the medications commonly used during pregnancy, Prospan ${ }^{\circledR}$ (dried extract of ivy leaf, Hedera helix), magnesium trisilicate mixture, dexamethasone and aspirin should be used with caution [4, 13-14]. The Australian Drug Evaluation Committee [13] recognised that emetine, a component of Hedera helix, and commonly used as an expectorant and mucolytic agent by pregnant women and women of childbearing age, did not increase the frequency of malformations. Nevertheless, the amount of emetine in Prospan ${ }^{\circledR}$ is not known and hence, until further evidence is available, the safety of Prospan ${ }^{\circledR}$ during pregnancy could not be confirmed. Safer expectorants such as guaifenesin should be considered instead [4].

Magnesium trisilicate mixture is generally considered as a safe antacid in pregnancy. However, magnesium trisilicate mixture has been associated with fetal nephrolithiasis, hypotonia and respiratory distress when used at high dosages and for a prolonged period. Calcium-based antacids are the preferred choice of antacids for pregnant women in any of the three trimesters [15].
Aspirin has been used to prevent intrauterine growth restrictions in pre-eclampsia and has also been used with or without heparin as a combination therapy to maintain pregnancy in women with a history of recurrent loss and antiphospholipid syndrome [17] Aspirin increases the risk of maternal and fetal haemorrhage when used during the first trimester $[13,18]$. In the third trimester, aspirin increases the risk of constriction of fetal ductus arteriosus, leading to pulmonary hypertension $[4,13]$. Therefore, it is advisable to take aspirin only at a low dosage of 50 to $150 \mathrm{mg}$ daily, if indicated [19].

Dexamethasone has been used in patients with premature labour to stimulate lung maturation and, thus, prevent respiratory distress syndrome [20]. The benefits of such treatment should be weighed carefully against the increased risk of cleft lip with or without cleft palate as well as other subsequent side effects on the child [21].

A total of seven potentially teratogenic medications were used by the pregnant respondents in the present study. Cafergot ${ }^{\circledR}$ contains ergotamine which is a vasoconstrictor and may impair blood flow to the fetus. Ergotamine also has oxytocic properties which can induce uterus contractions and spontaneous abortion. Headache in pregnant women usually improves after the first trimester and may not require any medication [22].

Infants exposed to antiepileptic medications have an increased risk of birth defects [23]. However, the use of antiepileptic medications has to be continued in pregnancy as their benefits usually outweigh the potential teratogenic risk [14]. Among the antiepileptic medications (such as lamotrigine, carbamazepine and sodium valproate), sodium valproate has the highest prevalence of major congenital malformations (MCM), $11.3 \%$ when used as monotherapy compared to lamotrigine (5.4\%) and carbamazepine (3.0\%) [24]. Prevalence of MCM is higher if the fetus is exposed to higher doses of sodium valproate $(>1000 \mathrm{mg} /$ day) or combination antiepileptic therapy, which included sodium valproate [24].

Sodium valproate was the second most commonly used antiepileptic agents among the general public in India [25]. These studies call for a change in the prescribing of sodium valproate as an antiepileptic medication for pregnant women. There is also an increased risk of neural tube defects associated with the use of antiepileptic medications and hence, women planning to get pregnant should be advised to start taking folic acid supplements prior to and during pregnancy [14]. It can be concluded that sodium valproate is best avoided during pregnancy if other alternatives are available. The risk of malformations can be minimised by using the lowest effective dose of sodium valproate, monotherapy of lamotrigine less than 300 $\mathrm{mg} /$ day or monotherapy of carbamazepine less than $400 \mathrm{mg} /$ day as well as the use of folic acid supplements $[14,26]$.

Propylthiouracil is considered as teratogenic because it suppresses the production of thyroid hormones in the mother and fetus, resulting in fetal hypothyroidism [27]. It also increases the risk of acute or severe liver injury in pregnant women [27-28]. However, the use of propylthiouracil is deemed necessary as untreated hyperthyroidism results in serious complications such as pregnancy-induced hypertension, thyroid storm, heart failure, premature labour, miscarriage and placental abruption. Other antithyroid medications such as carbimazole and methimazole had been associated with craniofacial malformations [28-29]. Therefore, the FDA, US still recommends propylthiouracil as the preferred antithyroid medication during the first trimester of pregnancy [28]. To avoid hepatotoxicity due to propylthiouracil, it is recommended to switch propylthiouracil to methimazole after the first trimester [30].

The chronic use of tramadol places the neonates at risk of withdrawal symptoms [31]. A better approach is to avoid the use of tramadol as other safer analgesics are available. Use of non-steroidal anti-inflammatory drugs (NSAIDs) such as diclofenac, during the third trimester of pregnancy, is associated with premature closure of ductus arteriosus, leading to pulmonary hypertension $[4,13]$. There is also evidence of increased risk of spontaneous abortions when NSAIDs are used during the first trimester [32]. Therefore, NSAIDs are best avoided during the first and third trimesters of pregnancy. 
Based on the available data, most of the medications taken by the pregnant women in the present study were prescribed by a doctor and were safe for use. Some authors of other studies suggested the need for a separate Rational and Essential Drug List for pregnancy [33]. However, patient education is still necessary to ensure that all pregnant women are aware of the risk of taking medications during pregnancy. During the consumption of medications, maternal health should be balanced with the risk of teratogenicity. Patients with medical conditions should plan their pregnancy and control their disease conditions prior to conception, to allow minimal usage of medications throughout their pregnancy.

There are several limitations in this study. Firstly, recall of medications used during pregnancy may be inaccurate or biased. Some respondents did not know the name of the medications they had taken despite efforts by the researcher to call these respondents after the initial interview, to check if they could recall the names of the medications taken. Therefore, the medical records of respondents were screened to confirm the medications used but non-prescription medications were often not included in these records.

Secondly, since this was a cross-sectional study, the use of medications throughout the respondents' pregnancy could not be captured as medications used after the interview could not be included. Thirdly, medications used just before pregnancy may have a cumulative effect on the fetus but these were not included in the study. In addition, the results of this study could not be generalised to medication use by pregnant women throughout Malaysia as the respondents were recruited from only one major hospital. However, this study can serve as a trigger for large-scale multicentre studies in order to obtain a better representation of medication use among pregnant women in Malaysia.

\section{CONCLUSION}

The use of medications by pregnant women in the present study was quite high (62\%). In addition, $30.8 \%$ of the pregnant women used at least one medication during the first trimester, the most common being analgesics, followed by cough and cold preparations. The use of antimigraine medications containing ergotamine in pregnant women is of major concern as this medication could be obtained without a prescription in some countries. The balance between the benefits and risks of using certain medications in pregnancy, such as antiepileptic medications requires due consideration. Therefore, it is essential for health care professionals to educate and counsel pregnant women on the safety of medications used.

\section{ACKNOWLEDGEMENT}

We are grateful to all the participants of this study as without their cooperation, this study would not have been possible. We would also like to thank Ms Goh Li Li for her assistance in collecting the data and all the staff of the antenatal clinic involved in this study for their cooperation and assistance. This study was supported by the University of Malaya Research Grant (RG 457/12HTM).

\section{AUTHORS' CONTRIBUTION}

JV KHO participated in the study design, reviewed the literature, collected, entered and analysed the data, and drafted the manuscript.

SS CHUA conceived the study, contributed to the design of the study, provided input on the pharmacy aspect of the study, analysed the data, and edited the manuscript.

RM DALLUMAL participated in the data analysis, reviewed the literature, formatted and edited the manuscript.

SZ OMAR participated in the design of the study, coordinated the data collection process, provided clinical input and edited the manuscript.

\section{CONFLICT OF INTERESTS}

All authors declare that they have no conflict of interest.

\section{REFERENCES}

1. Briggs GG, Freeman RK, Yaffe SJ. Drugs in pregnancy and lactation: a reference guide to fetal and neonatal risk. 6th ed. Baltimore: Lippincott Williams and Wilkins; 2001.

2. Wunsch MJ, Stanard V, Schnoll SH. Treatment of pain in pregnancy. Clin J Pain 2003;19:148-55.

3. McCarter-Spaulding DE. Medications in pregnancy and lactation. Am J Matern Child Nurs 2005;30:10-7.

4. Petrie K. Medications in pregnancy. In: Ratcliffe SD, Baxley EG, Cline MK, Sakornbut EL. editors. Family Medicine Obstetrics. 3rd ed. Philadelphia: Mosby Elsevier; 2008. p. 43-7.

5. US Food and Drug Administration. Pregnancy Outcomes Working Group of the FDA Pregnancy Labeling Taskforce. Reviewer Guidance Evaluating the Risks of Drug Exposure in Human Pregnancies [Internet]. Rockville (MD): Food and Drug Administration; 2005. Available from: http://www.fda.gov/ downloads/Drugs/./Guidances/ucm071645.pdf. [Last accessed on 26 Dec 2016]

6. Carney EW, Scialli AR, Watson RE, DeSesso JM. Mechanisms regulating toxicant disposition to the embryo during early pregnancy: an interspecies comparison. Birth Defects Res Part C 2004;72:345-60.

7. Mitchell AA, Gilboa SM, Werler MM, Kelly KE, Louik C, Hernández-Díaz S, et al. Medication use during pregnancy, with a particular focus on prescription drugs: 1976-2008. Am J Obstet Gynecol 2011;205:51.

8. Sharma R, Kapoor B, Verma U. Drug utilization pattern during pregnancy in North India. Indian J Med Sci 2006; 60:277-87.

9. Rahman AA, Sulaiman SA, Ahmad Z, Daud WNW, Hamid AM. Prevalence and pattern of use of herbal medicines during pregnancy in Tumpat District, Kelantan. Malaysian J Med Sci 2008;15:40-8.

10. Sooi LK, Keng SL. Herbal medicines: malaysian women's knowledge and practice. J Evidence-Based Complementary Altern. Med 2013:1-10. http://dx.doi.org/10.1155/2013/438139.

11. Rohra DK, Das N, Azam SI, Solangi NA, Memon Z, Shaikh AM, et al. Drug prescribing patterns during pregnancy in the tertiary care hospitals of Pakistan: a cross-sectional study. BMC Pregnancy Childbirth 2008;8:24.

12. WHO Collaborating Centre for Drug Statistics Methodology ATC/DDD Index; 2016. Available from: http://www.whocc.no/ atc_ddd_index/. [Last accessed on 15 Mar 2016]

13. Australian Drug Evaluation Committee. Prescribing medicines in pregnancy: An Australian categorization of risk of drug use in pregnancy. 4th ed. Canberra: Therapeutic Goods Administration; 1999.

14. British Medical Association and the Royal Pharmaceutical Society. British National Formulary. 65th ed. London: BMJ Publishing Group and Pharmaceutical Press; 2013.

15. Madanick RD, Katz PO. GERD and pregnancy. Pract Gastroenterol 2006;30:30-9.

16. Zaki NM, Albarraq AA. Use, attitudes and knowledge of medications among pregnant women: a Saudi study. Saudi Pharm J 2014;22:419-28.

17. James AH, Brancazio LR, Price T. Aspirin and reproductive outcomes. Obstet Gynecol Surv 2008;63:49-57.

18. Collins E, Turner G. Maternal effects of regular salicylate ingestion in pregnancy. Lancet 1975;306:335-8.

19. Bujold E, Roberge S, Lacasse Y, Bureau M, Audibert F, Marcoux $S$, et al. Prevention of preeclampsia and intrauterine growth restriction with aspirin started in early pregnancy: a metaanalysis. Obstet Gynecol 2010;116:402-14.

20. Roberts D, Dalziel S. Antenatal corticosteroids for accelerating fetal lung maturation for women at risk of preterm birth (review). Cochrane Database Syst Rev 2006;3:1-141.

21. Carmichael SL, Shaw GM, Ma C, Werler MM, Rasmussen SA, Lammer EJ. Maternal corticosteroid use and orofacial clefts. Am J Obstet Gynecol 2007;197:e1-7.

22. Menon R, Bushnell CD. Headache and pregnancy. Neurologist 2008;14:108-19.

23. Tomson T, Battino D. Teratogenic effects of antiepileptic drugs. Seizure 2008; 17:166-71. 
24. Mawer G, Briggs M, Baker GA, Bromley R, Coyle H, Eatock J, et al. Pregnancy with epilepsy: obstetric and neonatal outcome of a controlled study. Seizure 2010;19:112-9.

25. Mathur S, Sen S, Ramesh L, Satish Kumar M. Utilization pattern of antiepileptic drugs and their adverse effects, in a teaching hospital. Asian J Pharm Clin Res 2010;3:55-9.

26. Tomson T, Battino D, Bonizzoni E, Craig J, Lindhout D, Sabers A, et al. Dose-dependent risk of malformations with antiepileptic drugs: an analysis of data from the EURAP epilepsy and pregnancy registry. Lancet Neurol 2011;10:609-17.

27. Cooper DS, Laurberg P. Hyperthyroidism in pregnancy. Lancet Diabetes Endocrinol 2013;1:238-49.

28. US Food and Drug Administration. FDA Drug Safety Communication: New Boxed Warning on severe liver injury with propylthiouracil; 2006. Available from: http:// www.fda.gov/Drugs/DrugSafety/PostmarketDrugSafetyInform ationforPatientsandProviders/ucm209023.htm. [Last accessed on 04 Apr 2016].

29. Taylor PN, Vaidya B. Side effects of anti-thyroid drugs and their impact on the choice of treatment for thyrotoxicosis in pregnancy. Eur Thyroid J 2012;1:176-85.
30. Stagnaro-Green A, Abalovich M, Alexander E, Azizi F, Mestman $\mathrm{J}$, Negro $\mathrm{R}$, et al. Guidelines of the American Thyroid Association for the diagnosis and management of thyroid disease during pregnancy and postpartum. Thyroid 2011;21:1081-125.

31. Hudak ML, Tan RC. The committee on drugs, the committee on the fetus and newborn. Neonatal drug withdrawal. Pediatrics 2012;129:e540-60.

32. Li D, Liu L, Odouli R. Exposure to non-steroidal antiinflammatory drugs during pregnancy and risk of miscarriage: population based cohort study. $\mathrm{Br}$ Med J 2003;327:368-71.

33. Dhananjay S, Rahul AJ, Poonam K, Anita M. A cross-sectional, observational, prospective study for evaluation of rational drugs used during pregnancy. Int J Pharm Pharm Sci 2013;5:928-30.

\section{How to cite this article}

- Jey Vonn Kho, Siew Siang Chua, Rita Mohan Dallumal, Siti Zawiah Omar. Medications used by pregnant women: any safety concerns?. Int J Pharm Pharm Sci 2017;9(5):100-106. 